\title{
Mineral Transformation and Biomass Accumulation Associated With Uranium \\ Bioremediation at Rifle, Colorado
}

\author{
Li Li $^{\mathrm{a}^{*}}$, Carl I. Steefel ${ }^{\mathrm{a}}$, Kenneth H. Williams ${ }^{\mathrm{a}}$, Michael J. Wilkins ${ }^{\mathrm{b}}$, Susan S. Hubbard ${ }^{\mathrm{a}}$
}

${ }^{a}$ Lawrence Berkeley National Laboratory, Earth Sciences Division, 1 Cyclotron Road, MS 90-

1116, Berkeley, CA 94720

${ }^{\mathrm{b}}$ Department of Earth and Planetary Science, University of California, Berkeley, CA 94720

*Corresponding author

\section{Corresponding author contact information:}

Phone: 510-486-7540

Fax: 510-486-5686

Email: lili@1bl.gov

One sentence synopsis: Acetate injection for uranium bioremediation leads to the modification of the porosity of subsurface materials through the accumulation of new mineral phases and biomass.

Word count: 5496 (text) $+300 * 1$ (table $)+300 * 4$ (figures $)=6996$ 


\begin{abstract}
Injection of organic carbon into the subsurface as an electron donor for bioremediation of redoxsensitive contaminants like uranium often leads to mineral transformation and biomass accumulation, both of which can alter the flow field and potentially bioremediation efficacy. This work combines reactive transport modeling with a column experiment and field measurements to understand the biogeochemical processes and to quantify the biomass and mineral transformation/accumulation during a bioremediation experiment at a uranium contaminated site near Rifle, Colorado. We use the reactive transport model CrunchFlow to explicitly simulate microbial community dynamics of iron and sulfate reducers, and their impacts on reaction rates. The column experiment shows clear evidence of mineral precipitation, primarily in the form of calcite and iron monosulfide. At the field scale, reactive transport simulations suggest that the biogeochemical reactions occur mostly close to the injection wells where acetate concentrations are highest, with mineral precipitate and biomass accumulation reaching as high as $1.5 \%$ of the pore space. This work shows that reactive transport modeling coupled with field data can be an effective tool for quantitative estimation of mineral transformation and biomass accumulation, thus improving the design of bioremediation strategies.
\end{abstract}

\title{
Introduction
}

Uranium bioremediation involves injection of organic carbon into the subsurface to stimulate indigenous bacteria that reduce soluble U(VI) to insoluble U(IV) (1). Depending on the presence of electron acceptors in situ, a series of biogeochemical reactions can occur, with their products further reacting to form mineral precipitates such as iron sulfide and calcite (2) and low solubility gases such as methane (3). In addition, stimulated growth of bacteria leads to the accumulation of cell bodies and extracellular polymers (4). All of these lead to the reduction of pore space. In both pore-scale (5) and core-scale (6) experiments, it has been observed that biostimulation results in reduction of hydraulic conductivity and changes in dispersivity $(3,5)$. In field biostimulation 
experiments changes in tracer breakthrough data have been observed, indicating alteration in flow fields (7). Because the rate of uranium bioreduction can be affected by delivery of mobile electron donors through flow and transport processes, changes in flow fields can profoundly affect bioremediation efficacy. As such, it is important to quantify the changes in mineral and microbial community abundance.

This work focuses on a field-scale uranium bioremediation experiment conducted at the Department of Energy's Integrated Field Research Challenge (IFRC) site near Rifle, Colorado. Specific details regarding the site and the biostimulation experiment have been documented elsewhere $(1,8)$. Acetate was injected for two successive years (2002 and 2003) to investigate the effects of biostimulation for the purposes of remediation of uranium. Hydrological analysis has suggested changes in flow and conductivity fields during uranium bioremediation (9). Due to the negligible concentration of dissolved oxygen and nitrate, Fe-hydroxide reduction occurs after acetate injection, followed by sulfate reduction. Previous studies have shown a rapid increase in the abundance of iron-reducing bacteria (dominated by members of Geobacteraceae) during the early stage of field experiments, followed by rapid growth of sulfate reducers (1). The concentration of $\mathrm{U}(\mathrm{VI})$ decreases during the period of active iron-reduction, but rebounds somewhat following the onset of sulfate reduction, suggesting more efficient removal of U(VI) by the iron reducing community (1).

Although aqueous geochemistry data were routinely collected during field scale remediation experiments, direct observation of the evolution of mineral composition and biomass remains challenging, partly due to the associated expense and technical difficulty. Here we combine reactive transport modeling with column experiments to establish the biogeochemical reaction network, which was then used to match field aqueous geochemistry data. Based on a good match between modeling output and the field data, we estimate mineral transformations and biomass 
accumulation during the field experiments. Although direct quantitative verification of these estimates can be difficult, water chemistry provides an indirect indicator of the system dynamics and ensures the consistency of the estimation with the observed biogeochemistry. Used in this way, reactive transport modeling provides an efficient and costeffective tool not only to understand the dominant biogeochemical processes, but also to estimate changes in the aquifer properties. Although field bioremediation has been modeled before (e.g., 10), to our knowledge, this is the first study that integrates column and field experimental data to quantify the evolution of the mineral phases and biomass abundance associated with bioremediation at the field scale.

\section{Column and Field Experiments}

Column Experiment. Column experiments were carried out using groundwater and sediments obtained from the Rifle IFRC site. The groundwater was pumped from a location upgradient of the experimental area and was unimpacted by previous experiments at the site. The sediments were obtained through trenching and were sourced from a location beneath the water table at a depth of approximately $4 \mathrm{~m}$ below ground surface. The sediments and groundwater were kept in no-headspace vessels and stored at $4{ }^{\circ} \mathrm{C}$ in the dark until use. The sediments were sieved $(<4$ $\mathrm{mm}$ ) prior to being wet packed into $4.8 \mathrm{~cm}$ diameter by $30.5 \mathrm{~cm}$ long glass chromatography columns. The porosity of the sediments was determined to be $0.35 \pm 0.02$, yielding a pore volume of approximately $216 \mathrm{~cm}^{3}$. Prior to the addition of acetate, ten pore volumes of $\mathrm{N}_{2}$-sparged groundwater were passed through the column. Influent groundwater was then amended with 3 $\mathrm{mM}$ sodium acetate, de-gassed with ultra high purity $\mathrm{N}_{2}$, and sealed under the same gas headspace for the duration of the experiment (103 days). Groundwater was passed through the columns using a peristaltic pump with a flow rate of $125 \mu 1 / \min (0.83$ pore volumes per day), 
yielding a pore water velocity of $25.4 \mathrm{~cm} /$ day. Effluent samples were analyzed by ICP-MS and ICP-OES.

The field site and experiments. The Rifle IFRC site is part of the Uranium Mill Tailings Remedial Action (UMTRA) program of the U.S. Department of Energy. It is located on a flood plain of the Colorado River, with groundwater flow mainly within a gravelly sandy aquifer with an average hydraulic conductivity of approximately $35 \mathrm{~m} / \mathrm{d}$ and mean porosity of 0.27 . The groundwater contains dissolved uranium at the micromolar concentration level along with species such as $\mathrm{Ca}^{2+}, \mathrm{Mg}^{2+}, \mathrm{SO}_{4}{ }^{2-}$, and $\mathrm{HCO}_{3}{ }^{-}$, as listed in Table $\mathrm{S} 1$ in the Supporting Information. The minerals in the sediments include quartz, calcite, a variety of clays, and various iron-containing minerals, including iron (hydro)oxide (goethite, hematite, magnetite, and ferrihydrite). The amount of Fe-oxyhydroxide associated with the sediment varies significantly over space depending on the lithology of local sedimentary units. The Fe(III) content in the fine-grained sediment ( $<4 \mathrm{~mm}$ fraction) used for the column experiment is approximately $24.5 \mu \mathrm{mol} / \mathrm{g}$, measured by hydroxylamine reduction for 16 hours. A dithionite extraction (CBD) showed additionally $23.6 \mu \mathrm{mol} / \mathrm{g}$ of $\mathrm{Fe}$ in more crystalline Fe-oxide phases. The sediments include both coarse-grained material (gravels and cobbles), as well as beds of fine-grained silt and clay. If weighted by the percentage of fine-grained material in the sediments, the adjusted extractable iron content (including both the $0.5 \mathrm{~N}$ hydroxylamine and CBD extractable) would be about 26 $\mu \mathrm{mol} / \mathrm{g}$, and the adjusted hydroxylamine extractable iron is about $13 \mu \mathrm{mol} / \mathrm{g}$. The amount of "bioavailable" Fe(III) was obtained by fitting both the column and field experimental data.

During the field experiments, acetate and bromide were mixed with background groundwater and injected into the subsurface for 119 days in 2002 and for 111 days in 2003 . There were three rows of monitoring wells located at approximately $3.7,7.3$, and $14.6 \mathrm{~m}$ downgradient from the 
injection gallery. During the field experiments, aqueous geochemical data, including $\mathrm{pH}$, concentrations of acetate, $\mathrm{Br}-, \mathrm{Fe}(\mathrm{II}), \mathrm{S}(-\mathrm{II}), \mathrm{SO}_{4}{ }^{2-}$, and $\mathrm{U}(\mathrm{VI})$, were collected periodically. Detailed information on the test plot, the measurements of field aqueous geochemistry before and after the acetate injection, as well as the characterization of the mineralogy and hydrogeology were published elsewhere $(1,8)$.

\section{Reactive Transport Modeling}

This section provides a brief introduction on the key elements involved in modeling. More details are provided in Supplemental Information. The code CrunchFlow (11), a software for modeling multicomponent reactive flow and transport (12), was used to simulate the reactive transport processes for both column and field experiments. The reaction network includes both kinetic and instantaneous reactions. The kinetic reactions include microbially-mediated reduction of uranium, bioavailable iron hydroxide, and sulfate, as well as mineral dissolution and precipitation. These reactions, together with instantaneous reactions such as sorption/desorption and ion exchange, are listed in Table 1. Aqueous speciation reactions are listed in Table S2 in the Supporting Information.

The microbially-mediated reactions were formulated so as to partition electron donors between respiration and cell growth according to the microbial energetics (13). Iron reducing and sulfate reducing bacteria (FeRB and SRB) are represented by formula $\mathrm{C}_{5} \mathrm{H}_{7} \mathrm{O}_{2} \mathrm{~N}_{(\mathrm{FeRB})}$ and $\mathrm{C}_{5} \mathrm{H}_{7} \mathrm{O}_{2} \mathrm{~N}_{(\mathrm{SRB})}$, respectively, and are considered as reaction products. The rates of the reactions were modeled using a dual Monod rate expression with an inhibition term, which simulates the successive redox sequence of electron acceptors. The rate law explicitly incorporates the dependence of the rate on the biomass, as shown in the following equation, 


$$
r_{s}=-k_{\max } X_{S} \frac{C_{S}}{K_{M, S}+C_{S}} \frac{C_{T E A}}{K_{M, T E A}+C_{T E A}} \frac{K_{I}}{K_{I}+C_{I}}
$$

Here the reaction rate $r_{s}$ of substrate $S$ depends on the maximum utilization rate $k_{\max }(\mathrm{mol} / \mathrm{L}-\mathrm{s}-$ cells), the concentration of the bacteria that degrade the substrate $X_{S}$ (cells), the concentrations of the substrate $\left(C_{S}\right)$ and that of the terminal electron donor $\left(C_{T E A}\right)$ through the dual Monod terms with their respective half-saturation constants $K_{M, S}$ and $K_{M, T E A}(\mathrm{~mol} / \mathrm{L})$, as well as the inhibition term, with $K_{I}$ being the inhibition constant $(\mathrm{mol} / \mathrm{L})$ and $C_{I}$ being the concentration of the inhibiting substance $I(\mathrm{~mol} / \mathrm{L})$. Here sulfate reduction is assumed to be inhibited by iron hydroxide present locally while iron and uranium reduction is not inhibited due to the negligible concentrations of dissolved oxygen and nitrate.

The biomass is conceptually modeled as an immobile phase based on literature observations that bacterial cells usually associate with the solid phase as a biofilm or as discrete biomass colonies (13). The bacteria grow as the products of the reduction reactions at the rate specified by Equation (1), which is in turn affected by the amount of bacteria produced. As such, the model explicitly simulates the microbial community dynamics and includes the effects of the dynamic evolution on microbially-mediated reaction rates (14).

Table 1. Important reactions resulting from biostimulation and their kinetic and thermodynamic parameters

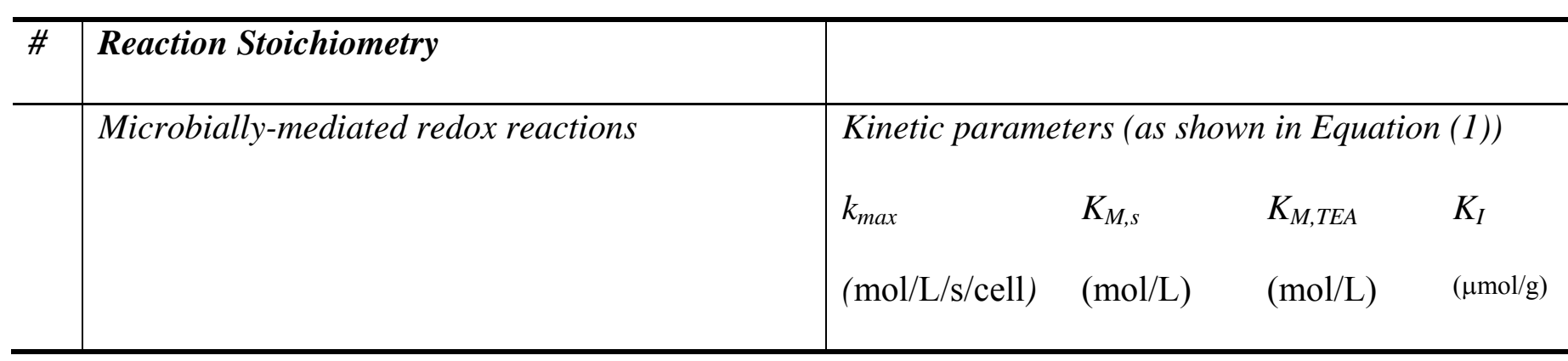




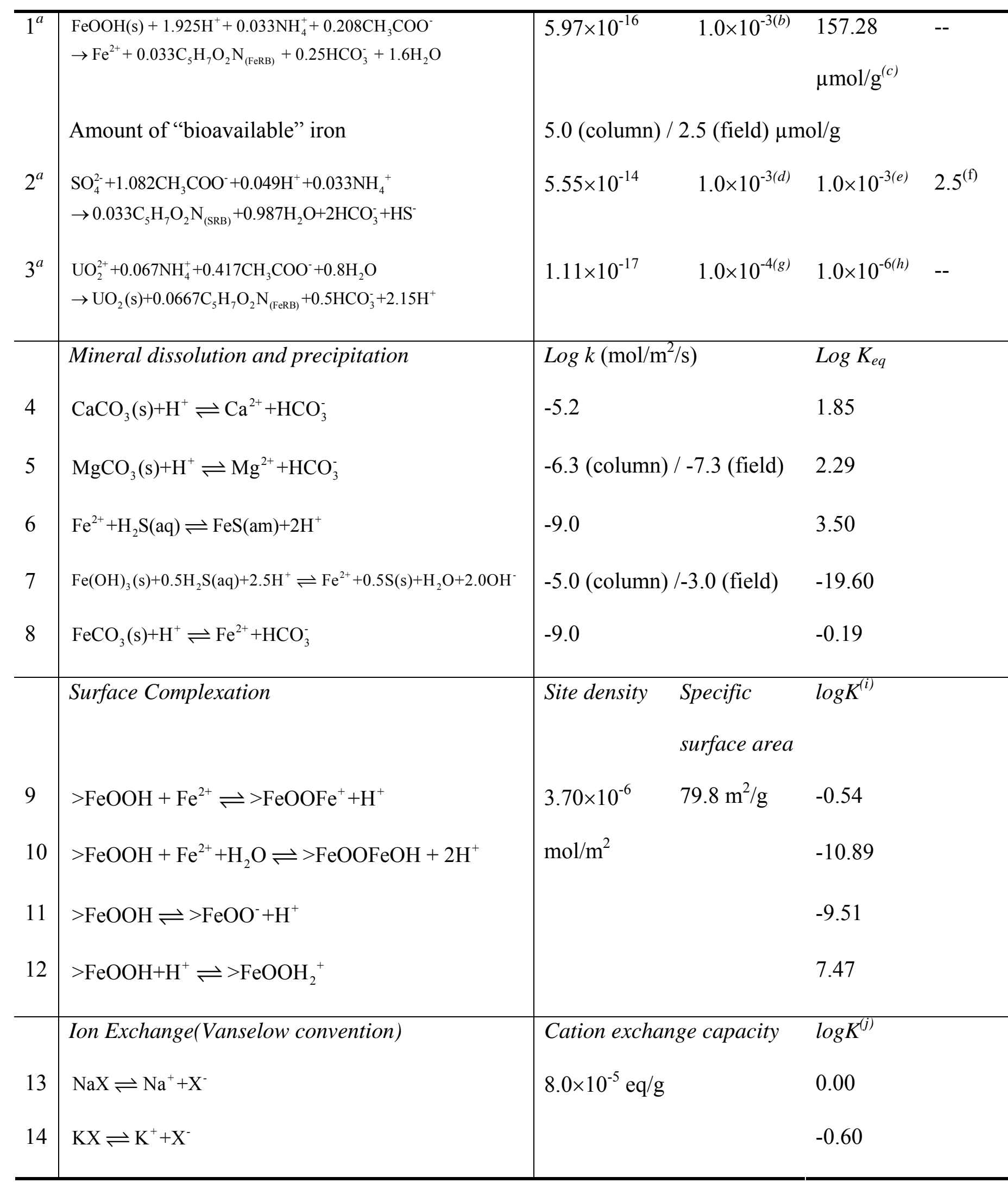




\begin{tabular}{l|l|c}
\hline 15 & $\mathrm{CaX}_{2} \rightleftharpoons \mathrm{Ca}^{2+}+2 \mathrm{X}^{-}$ & -0.50 \\
\cline { 1 - 2 } & $\mathrm{MgX}_{2} \rightleftharpoons \mathrm{Mg}^{2+}+2 \mathrm{X}^{-}$ & \\
\hline
\end{tabular}

\footnotetext{
${ }^{a}$ See details in Supporting Information for the derivation of the reactions. ${ }^{b}(15) .{ }^{c}$ Range between 10.5 to $235.0 \mu \mathrm{mol} / \mathrm{g}(16,17) .{ }^{d}$ Range between 0.0043 to $0.1 \mathrm{mM}$ (18). ${ }^{e}$ Range between 0.1 to $7.5 \mathrm{mM}(19,20) .{ }^{f}$ Range between 0.8 to $5 \mu \mathrm{mol} / \mathrm{g}(8,21) .{ }^{g}$ no literature data available. ${ }^{h}$ Range between 0.0001 to $24 \mathrm{mM}(21,22) .{ }^{i}$ All surface complexation parameters are from $(23) .{ }^{j}$ All $\log$ $\mathrm{K}$ values from (24).
}

The rates of mineral dissolution and precipitation, including the abiotic reduction of $\mathrm{Fe}(\mathrm{OH})_{3}$ by $\mathrm{H}_{2} \mathrm{~S}$ (25), follow a rate law derived from Transition State Theory (TST) (26). All reaction rate constants, including the $k_{\max }$ values for the microbially-mediated reactions and the logk values for the mineral dissolution and precipitation, and the amount of bioavailable Fe(III), are obtained through calibration for the field data and are listed in Table 1. All other kinetic and thermodynamic parameters were taken from literature. Data from the column experiments were used to determine the dominant reactions involved during uranium bioremediation. The same reaction network was then applied to simulate the field experiments using $1 \mathrm{D}$ reactive transport modeling. Based on the constraints provided by the field aqueous data, the temporal evolution of the solid phase composition and the amount of biomass were determined.

The domain for the field experiment is considered homogeneous, with a constant porosity of 0.27 and permeability of $7.28 \times 10^{-12} \mathrm{~m}^{2}$. The simulations were carried out within a 24 meter domain, with 480 nodes and a resolution of $5.0 \mathrm{~cm}$. The dispersion coefficient was chosen to be $0.40 \mathrm{~m}$ to best fit the tracer field data, also a typical value at a spatial scale of tens of centimeters (27). The initial and boundary conditions for the aqueous species were the measured background composition at Rifle, as listed in Table S1. Initially both FeRB and SRB were considered to exist 
ubiquitously, occupying $10^{-4}$ volume percentage of the solid phase, and corresponding to a cell density of $10^{4}$ to $10^{7}$ cells $/ \mathrm{ml}$ of the sediment, a typical range of cell density for natural sediments (19). The simulations were carried out with the initial conditions of the 2003 experiment set to be the final state of the 2002 experiment.

This work extends previous modeling efforts (8) for the Rifle site in several ways: 1) a complete reaction network was developed from the column experiments; 2) biomass growth was modeled to keep track of the evolution of the iron and sulfate reducing populations; 3) rate laws for microbially-mediated reactions explicitly incorporated the impact of biomass growth; 4) the focus of the modeling was on a quantitative estimation of mineral transformation and biomass accumulation; and 5) all field aqueous data measured were used as constraints (not just bromide, acetate, U(VI), and sulfate).

\section{Results and Discussion}

Reaction network based on column experiments. As indicated by the increase in the effluent $\mathrm{Fe}(\mathrm{II})$ in Figure 1, the injection of acetate led to the reductive dissolution of iron hydroxide. After about 25 days, presumably accompanying the near depletion of bioavailable iron hydroxide as indicated by modeling results, the increasing activity of sulfate reducing bacteria began, which led to the decrease in concentrations of sulfate and Fe(II). The sulfide species reacted with ferrous ion to form iron sulfide, indicated by the accumulation of visibly dark regions along the column (Figure S1). The effluent $\mathrm{pH}$ increased significantly over time in the column, reaching as high as 8.5 , in contrast to the fairly constant $\mathrm{pH}$ of 7.0 in the field experiments. The increase in the column $\mathrm{pH}$ appears to be due to the use of a $100 \% \mathrm{~N}_{2}$ headspace, which resulted in degassing of initially $1 \% \mathrm{CO}_{2}$ from the groundwater in the column. In the model we simulate this as a process of $\mathrm{CO}_{2}$ depletion, driving the $\mathrm{pH}$ from 7.0 initially to 8.5 at later times. Alkalinity increased as a 
result of the acetate oxidation, causing calcite precipitation as confirmed by the decrease in $\mathrm{Ca}^{2+}$ concentration at later time points. In addition, modeling results suggested that magnesite and siderite could have precipitated as the alkalinity increased, although this has not been confirmed by destructive characterization. Elemental sulfur precipitated due to the reductive dissolution of iron oxide by $\mathrm{H}_{2} \mathrm{~S}$ is also predicted by the modeling.
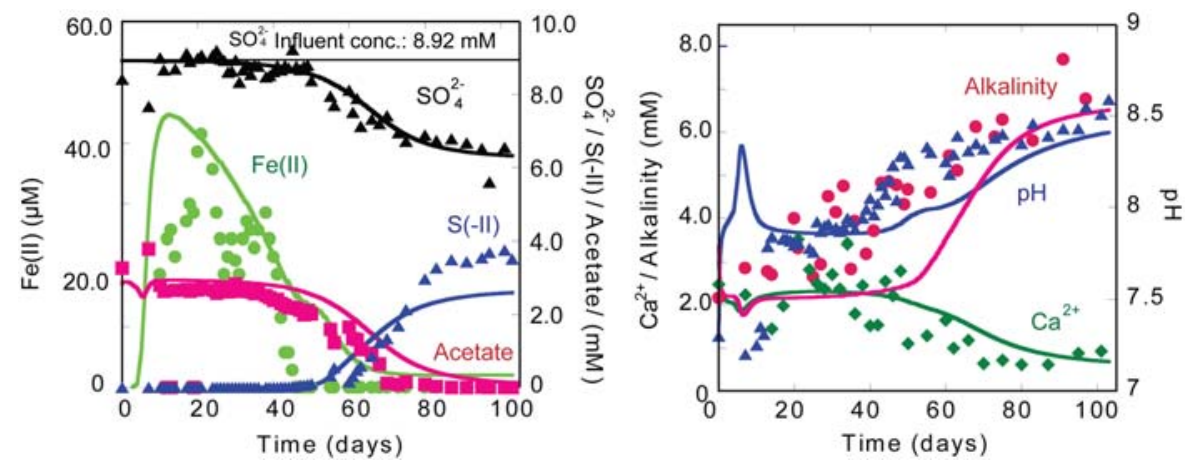

Figure 1: Comparison of column experiment data (symbols) with modeling results (solid lines) for various aqueous species. The good match between experiment and modeling data indicate the validity of the developed reaction network.

Modeling of field experiments. The reaction network inferred from the column experiment was used in the simulation of the field experiments. The modeling results were compared with the measured aqueous concentrations averaged over the five monitoring wells within each row for the field experiments in 2002 and 2003, as shown in Figure 2 and Figure S2, respectively. Compared to the column experiments, the field data are much more variable as indicated by the large error bars corresponding to the double standard deviation range of the averaged concentrations; this variability is likely due to the spatial variation in aqueous geochemistry and aquifer properties. Although the same reaction network was applied, some of the parameters had to be adjusted for the field data in order to obtain a good fit. For example, the initial bioavailable Fe(III) content was changed from $5.0 \mu \mathrm{mol} / \mathrm{g}$ in the column experiments to $2.5 \mu \mathrm{mol} / \mathrm{g}$ in the field. This is likely 
due to the fact that the column experiment used the $<4 \mathrm{~mm}$ fraction of the sediment, which contains a higher Fe(III) content than does the coarse fraction present as well in the field experiment. The amount of bioavailable Fe(III) predicted from modeling comprises about $10 \%$ of the hydroxylamine extractable Fe(III) for fine-grained sediments used in the column (about 24 $\mu \mathrm{mol} / \mathrm{g}$ ) and $20 \%$ of the hydroxylamine extractable $\mathrm{Fe}(\mathrm{III})$ for field sediments (about 13.0 $\mu \mathrm{mol} / \mathrm{g}$ ). This may seem a small percentage; however, these numbers fall into the reported percentages of low or medium surface area crystalline $\mathrm{Fe}(\mathrm{III})$ that can be used by bacteria $(8 \%$ to $18 \%)(17)$.

The field data suggested a similar sequence of redox reactions to what is observed in the column experiments, as indicated by an early increase in $\mathrm{Fe}(\mathrm{II})$ concentration, a later decrease in $\mathrm{SO}_{4}{ }^{2-}$ concentration and increase in S(-II) concentration. In general, as shown in Figure 2, the model has captured the biogeochemical dynamics in the field. Except for the $\mathrm{pH}$ values at early times, the modeling results match the average field data very well. The good fit of the solute breakthrough data provides a solid foundation for the estimation of solid phase composition and biomass accumulation. Significantly, such good fit was possible only after explicitly modeling the microbial community dynamics and its impact on the rates of microbially-mediated reactions.
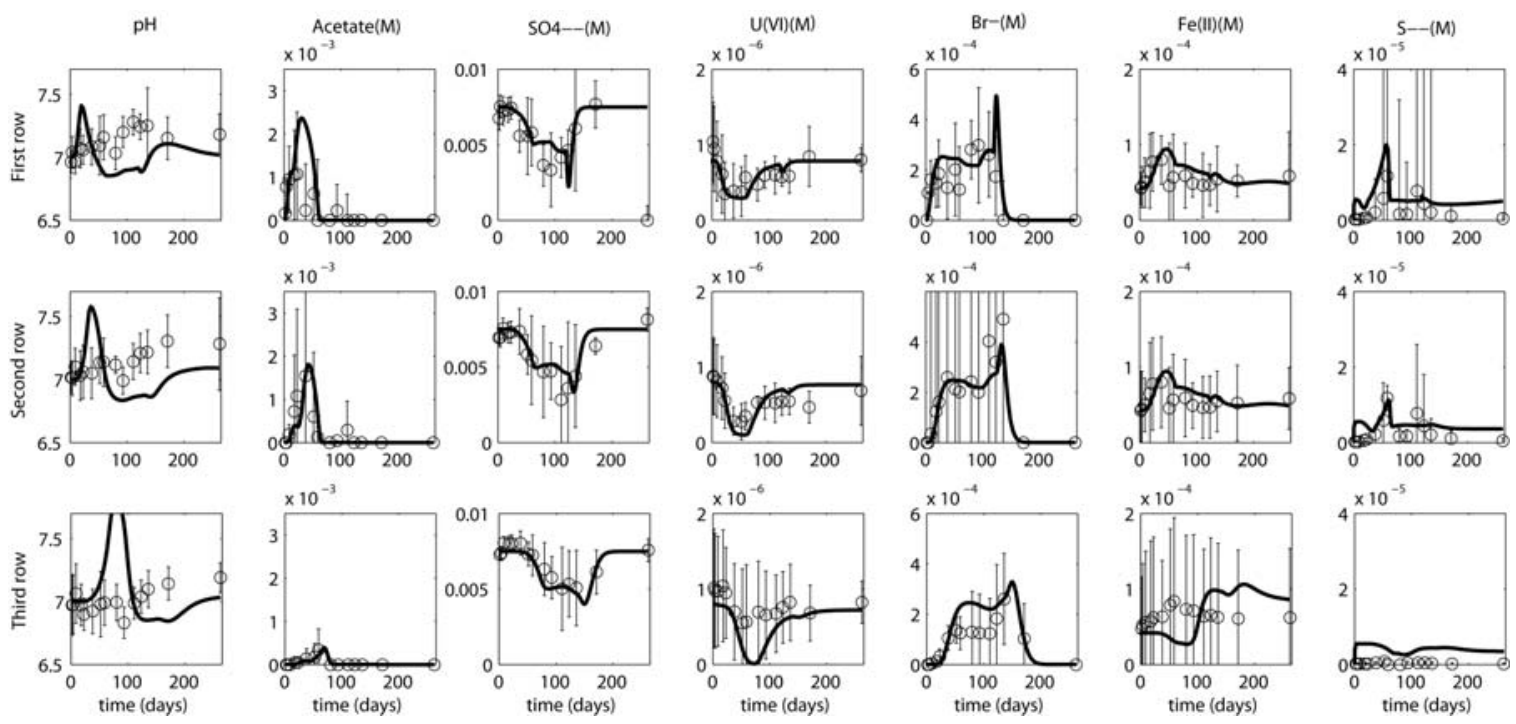
Figure 2: Comparison between 2002 averaged field data for each row (dots) and the 1D modeling results (lines). The error bars show the spatial variation of the data within each row of monitoring wells. The size of the error bar is double standard deviation range of the averaged concentrations.

Estimation of mineral transformation and biomass accumulation. Based on the good fit to field aqueous geochemistry data, the change in the solid phase composition and the amount of biomass accumulation were estimated. Figure 3 shows the temporal evolution of important minerals. After acetate injection, the bioavailable iron hydroxide was consumed initially within regions close to the injection wells and this zone of Fe-hydroxide depletion expanded over time in the downgradient direction. Most microbially-mediated Fe reduction occurred within the first 50 days in 2002. In addition to enzymatic reduction by bacteria, iron oxide was also reduced abiotically by $\mathrm{H}_{2} \mathrm{~S}$ generated from sulfate reduction. As shown in Figure 3B, this pathway actually consumed much more $\mathrm{Fe}(\mathrm{OH})_{3}$ (with a maximum value of $0.13 \%$ of the pore space, equivalent to $6.9 \mu \mathrm{mol} / \mathrm{g}$ sediments at the end of 2003) than the microbially-mediated Fe reduction did. Calcite and $\mathrm{FeS}(\mathrm{am})$ are predicted to be the primary precipitates, with maximum accumulation close to the injection wells. Although not shown in Figure 3, elemental sulfur also precipitated according to the modeling. Its time evolution mirrors that of the $\mathrm{H}_{2} \mathrm{~S}$-reacted iron hydroxide (3B), being stoichiometrically equal to half of the $\mathrm{Fe}(\mathrm{OH})_{3}$ reacted in this way on a molar basis. In addition, modeling results suggest that siderite, magnesite, and $\mathrm{UO}_{2}(\mathrm{~s})$ precipitated, although in much smaller quantities. 

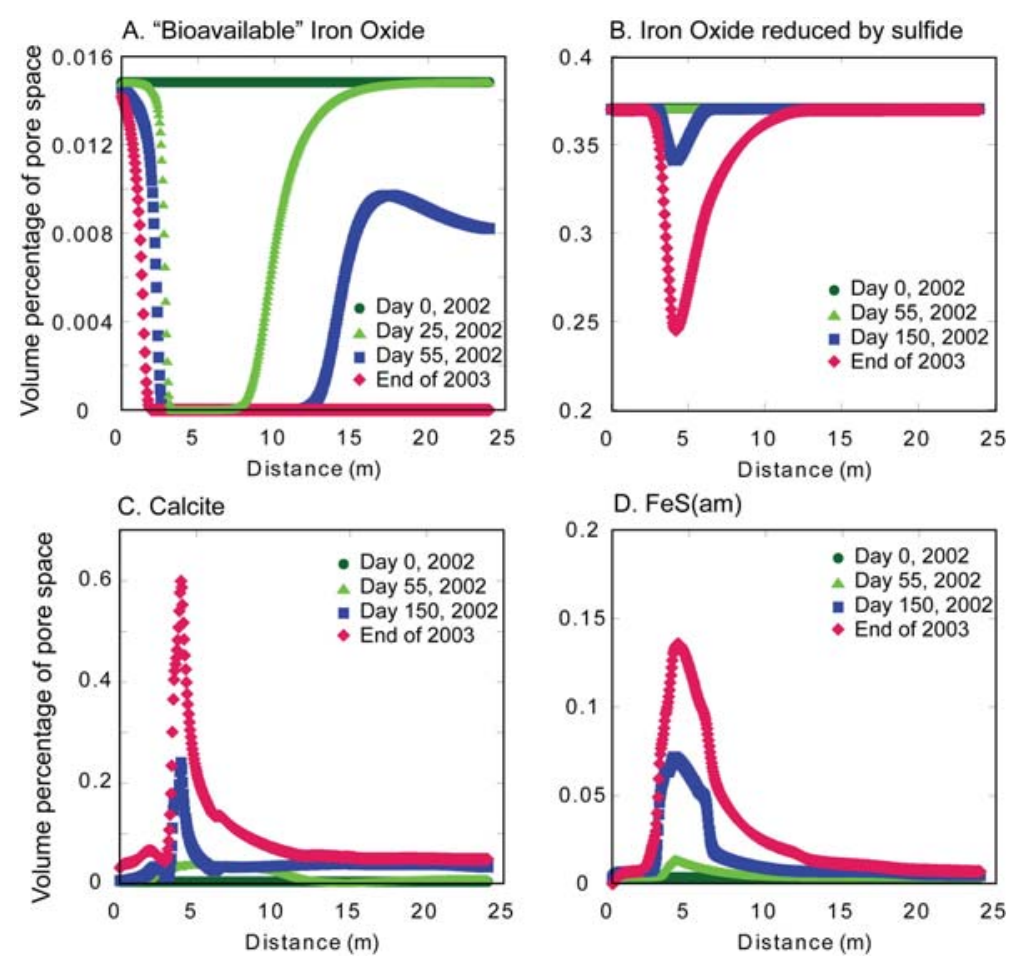

Figure 3: The time evolution of volume percentage of the pore space occupied by various minerals. The average ground water direction is toward the right. The injection wells are at a distance of $3.7 \mathrm{~m}$.
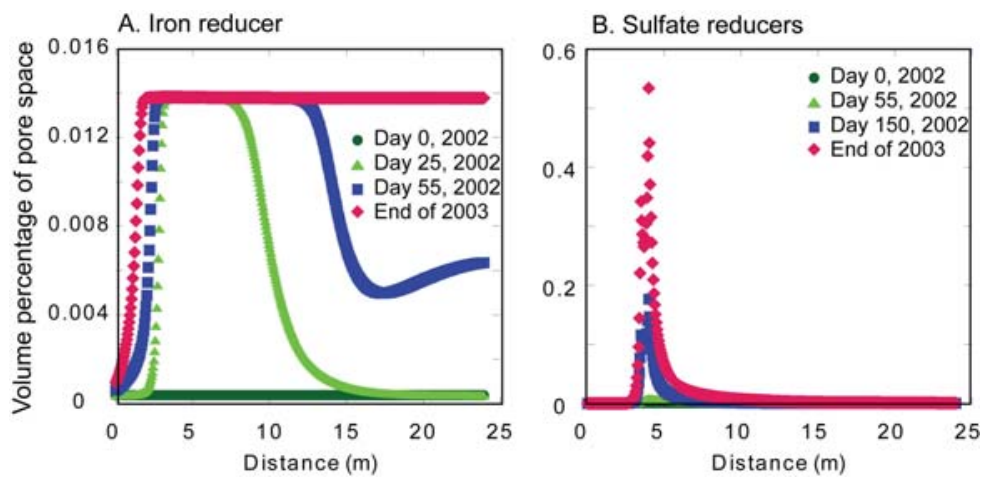

Figure 4: The time evolution and spatial distribution of volume percentage of the pore space occupied by iron and sulfate reducing bacteria.

For the biomass, the time evolution of the iron and sulfate reducers differs significantly, as shown in Figure 4. For the first 50 days in 2002 the FeRB grew rapidly, while the sulfate reducers remained negligible due to the inhibition of the sulfate reduction pathway until exhaustion of the 
bioavailable iron hydroxide. In addition, the spatial distribution of the two microbial populations differs. Initially the FeRB grew in the vicinity of the injection wells, and then expanded downgradient to areas with more bioavailable iron hydroxide. In contrast, SRB accumulate mostly at the location of injection wells, while at other locations the accumulation is orders of magnitude smaller. This is due to two reasons: 1) the concentration of sulfate is so high that the amount of acetate injected is never large enough to consume all of it, with the result that acetate is depleted close to the injection well, and 2) sulfate is present in the groundwater and therefore is continuously replenished from upgradient, thus fixing the sulfate reduction zone in space. In addition, the accumulation of SRB was much higher in 2003 than in 2002, largely because the amount of acetate injected was approximately 3 times higher in 2003 than it was in 2002. The localization of sulfate reduction in the vicinity of the injection wells also explains why most of mineral dissolution and precipitation occurs there as well, since these are driven by their reaction products (alkalinity, sulfide, $\mathrm{Fe}(\mathrm{II})$ ). In total, the amount of precipitates and biomass reach as high as $1.5 \%$ of the overall pore volume close to the injection wells.

Advantages and limitations of the model. This work applied the reaction network from the column experiments to the field system and estimated the spatial distribution of mineral precipitates and biomass associated with an in-situ biostimulation. Although quantitative verification of such estimation can be difficult, it is at least qualitatively verifiable. For example, the fact that biochemical activity occurs closely to the injection wells has been observed by previous studies (1). As such, the modeling can at least direct data collection activities in future bioremediation experiments. The good match obtained between modeling output and field data suggests that the column experiments have captured the major biogeochemical dynamics in the field system. However, some of the parameters had to be changed due to the differences between the column and field systems, including the amount of "bioavailable" iron. This indicates that although the column experiments can be an analogue of the field system, not all features of the 
field systems can be captured. Systems such as flow cell experiments may better represent the heterogeneous nature of the field system. The modeling results also suggest that the "bioavailable iron" is only a very small percentages of the total iron oxide present. This may be a consequence of assuming that redox reactions occur in sequence. Although this is true thermodynamically and have been observed in many field systems, there have also been observations that different redox reactions can occur in parallel under certain conditions (28).

Importance of explicitly modeling microbial community structure. The maximum rate of $\mathrm{Fe}(\mathrm{III})$ reduction occurred at the point where the reaction front was formed. The highest reaction rate occurred close to the injection wells initially and propagated downgradient over time. For sulfate reduction, no such downgradient propagation was predicted; however, the several orders of magnitude increase in SRB close to injection wells caused a commensurate increase in the reduction rates following Equation (1). Although not shown here, a reaction rate without a dependence on the amount of biomass leads to an underestimation of rates close to the injection wells and an overestimation of rates downgradient, indicating the importance of explicitly modeling the spatial and temporal evolution of microbial communities.

Possibility of pore clogging. The total amount of accumulated biomass and precipitates may seem small (up to $1.5 \%$ of the pore space), but the effects on the physical and chemical properties of the aquifer can be significant. How the precipitates and biomass clog the pore space depends on the details of where the reactions occur and the pore size distribution of the sediments. Multiple studies have shown that it is easier to clog a porous medium with fine-grained materials (29-31). The current estimate is based on the assumption that the system is a homogeneous system with uniform distributions of aquifer properties. As such, the estimate indicates the "average" behavior of the system. Because the Rifle aquifer is actually heterogeneous and contains both coarse-grained and fine-grained sediments (32), it is possible that such 
heterogeneity can have a significant local impact, resulting in preferential clogging of pores within the fine-grained sediments. The effect of heterogeneities on mineral transformation and biomass accumulation is the topic of another study (33).

Although the biomass accumulated in similar amounts to the mineral precipitates, it is likely to have a larger impact on pore clogging. Biomass not only occupies the pore space by volume, but also produces materials like extracellular polymeric substance (EPS), which is sheet-like and can decrease the flow-conducting volume (34). Using a relationship between conductivity reduction and the amount of biomass accumulated (6), the volume reduction at the location of the injection wells reached as high as a factor of 0.037 (or more than one order of magnitude) by the end of 2003.

Environmental implications for bioremediation. To the best of our knowledge, this is the first field-scale study on quantification of mineral transformation and biomass accumulation associated with biostimulation. Although a few field bioremediation studies have indicated or demonstrated alteration in flow fields $(7,9)$, this study suggests that in situ bioremediation activities involving organic carbon amendment can generate clogging processes in the vicinity of injection wells where the highest concentrations of organic carbon exist. The results suggest that to maximize the bioremediation efficacy, it is important to carefully design the injection wells and their spatial location to minimize the impact of clogging processes. In addition, specific injection conditions, such as the concentration of organic carbon and its rate of injection, will also be important in minimizing pore clogging. In this context, reactive transport modeling, coupled with the requisite field data, can serve as an efficient and cost-effective tool to integrate the effects of complex biogeochemical and transport processes that occur in situ, to quantitatively estimate the temporal and spatial evolution of the precipitates and biomass in different injection scenarios, and to help improve bioremediation strategies. 


\section{Acknowledgments}

Funding for this study was provided by the U.S. Department of Energy, Biological and Environmental Research Program Contract DE-AC02-05CH11231 to the LBNL Sustainable Systems Scientific Focus Area. We also acknowledge Phil Long (PNNL) and the Rifle IFRC research team for facilitating collaboration and access to Rifle datasets. We thank the reviewers for constructive comments that have improved the paper.

\section{Supporting Information Available}

Details of reactive transport modeling and simulation conditions are provided in the Supporting Information. This information is available free of charge via the Internet at http://pubs.acs.org.

\section{Literature Cited}

(1) Anderson, R. T.; Vrionis, H. A.; Ortiz-Bernad, I.; Resch, C. T.; Long, P. E.; Dayvault, R.; Karp, K.; Marutzky, S.; Metzler, D. R.; Peacock, A.; White, D. C.; Lowe, M.; Lovley, D. R. Stimulating the in situ activity of Geobacter species to remove uranium from the groundwater of a uranium-contaminated aquifer. Appl. Environ. Microbiol. 2003, 69, 5884-5891.

(2) van Beek, C. G. E. M.; van der Kooij, D. Sulfate-reducing bacteria in ground water from clogging and non-clogging shallow wells in the Netherlands river region. Ground Water 1982, 20, 298-302.

(3) Baveye, P.; Vandevivere, P.; Hoyle, B. L.; DeLeo, P. C.; de Lozada, D. S. Environmental impact and mechanisms of the biological clogging of saturated soils and aquifer materials. Crit. Rev. Env. Sci. Technol. 1998, 28, 123-191. 
(4) Vandevivere, P.; Baveye, P. Effect of Bacterial Extracellular Polymers on the Saturated Hydraulic Conductivity of Sand Columns. Appl.Environ. Microbiol. 1992, 58, 1690-1698.

(5) Dupin, H. J.; McCarty, P. L. Mesoscale and microscale observations of biological growth in a silicon pore imaging element. Environ. Sci. Technol. 1999, 33, 1230-1236.

(6) Taylor, S. W.; Jaffe, P. R. Biofilm Growth and the Related Changes in the Physical-Properties of a Porous-Medium .1. Experimental Investigation. Water Resour. Res. 1990, 26, 2153-2159.

(7) Faybishenko, B.; Hazen, T. C.; Long, P. E.; Brodie, E. L.; Conrad, M. E.; Hubbard, S. S.; Christensen, J. N.; Joyner, D.; Borglin, S. E.; Chakraborty, R.; Williams, K. H.; Peterson, J. E.; Chen, J. S.; Brown, S. T.; Tokunaga, T. K.; Wan, J. M.; Firestone, M.; Newcomer, D. R.; Resch, C. T.; Cantrell, K. J.; Willett, A.; Koenigsberg, S. In Situ Long-Term Reductive Bioimmobilization of Cr(VI) in Groundwater Using Hydrogen Release Compound. Environ. Sci. Technol. 2008, 42, 8478-8485.

(8) Yabusaki, S. B.; Fang, Y.; Long, P. E.; Resch, C. T.; Peacock, A. D.; Komlos, J.; Jaffe, P. R.; Morrison, S. J.; Dayvault, R. D.; White, D. C.; Anderson, R. T. Uranium removal from groundwater via in situ biostimulation: Field-scale modeling of transport and biological processes. J. Contam. Hydrol. 2007, 93, 216-235.

(9) Englert, A.; Hubbard, S. S.; Williams, K. H.; Li, L.; Steefel, C. I. Characterization of Field Scale Altering Transport Behavior During Stimulated Bioremediation. Environ. Sci. Technol. 2009 (submitted).

(10) Scheibe, T. D.; Fang, Y.; Murray, C. J.; Roden, E. E.; Chen, J.; Chien, Y.-J.; Brooks, S. C.; Hubbard, S. S. Transport and biogeochemical reaction of metals in a physically and chemically heterogeneous aquifer. Geosphere 2006, 2, doi: 10.1130/GES00029.00021.

(11) Steefel, C. I. "CrunchFlow User's Manual," Lawrence Berkeley National Laboratory, 2007. (12) Steefel, C. I.; MacQuarrie, K. T. B. Approaches to modeling of reactive transport in porous media. In Reactive Transport in Porous Media; Lichtner, P. C., Steefel, C. I., Oelkers, E. H., Eds.; The Mineralogical Society of America: Washington, D.C., 1996; Vol. 34, pp 83-130. 
(13) Rittmann, B. E.; McCarty, P. L. Environmental Biotechnology: Principles and Applications; McGraw-Hill: New York, 2001.

(14) Dale, A. W.; Regnier, P.; Van Cappellen, P. Bioenergetic controls on anaerobic oxidation of methane (AOM) in coastal marine sediments: A theoretical analysis. Am. J. Sci. 2006, 306, 246294.

(15) Liu, C. X.; Kota, S.; Zachara, J. M.; Fredrickson, J. K.; Brinkman, C. K. Kinetic analysis of the bacterial reduction of goethite. Environ. Sci. Technol. 2001, 35, 2482-2490.

(16) Bonneville, S.; Van Cappellen, P.; Behrends, T. Microbial reduction of iron(III) oxyhydroxides: effects of mineral solubility and availability. Chem. Geol. 2004, 212, 255-268. (17) Roden, E. E.; Zachara, J. M. Microbial reduction of crystalline iron(III) oxides: Influence of oxide surface area and potential for cell growth. Environ. Sci. Technol. 1996, 30, 1618-1628. (18) Jung, J.; Hyun, S. P.; Lee, J. K.; Cho, Y. H.; Hahn, P. S. Adsorption of $\mathrm{UO}_{2}{ }^{2+}$ on natural composite materials. J. Radioanal.Nucl. Chem. 1999, 242, 405-412.

(19) Pallud, C.; Van Cappellen, P. Kinetics of microbial sulfate reduction in estuarine sediments. Geochim. Cosmochim. Acta 2006, 70, 1148-1162.

(20) Porter, D.; Roychoudhury, A. N.; Cowan, D. Dissimilatory sulfate reduction in hypersaline coastal pans: Activity across a salinity gradient. Geochim. Cosmochim. Acta 2007, 71, 51025116.

(21) Wang, S.; Jaffe, P. R.; Li, G.; Wang, S. W.; Rabitz, H. A. Simulating bioremediation of uranium-contaminated aquifers; uncertainty assessment of model parameters. J. Contam. Hydrol. 2003, 64, 283-307.

(22) Boonchayaanant, B.; Kitanidis, P. K.; Criddle, C. S. Growth and cometabolic reduction kinetics of a uranium- and sulfate-reducing Desulfovibrio Clostridia mixed culture: Temperature effects. Biotechnol.Bioeng. 2008, 99, 1107-1119.

(23) Dixit, S.; Hering, J. G. Sorption of Fe(II) and As(III) on goethite in single- and dual-sorbate systems. Chem. Geol. 2006, 228, 6-15. 
(24) Charlet, L.; Tournassat, C. Fe(II)-Na(I)-Ca(II) cation exchange on montmorillonite in chloride medium: Evidence for preferential clay adsorption of chloride - Metal ion pairs in seawater. Aquat. Geochem. 2005, 11, 115-137.

(25) Yao, W. S.; Millero, F. J. Oxidation of hydrogen sulfide by hydrous Fe(III) oxides in seawater. Mar. Chem. 1996, 52, 1-16.

(26) Lasaga, A. C. Kinetic theory in the earth sciences; Princeton University Press: Princeton, 1998.

(27) Gelhar, L. W.; Welty, C.; Rehfeldt, K. R. A Critical-Review of Data on Field-Scale

Dispersion in Aquifers. Water Resour. Res. 1992, 28, 1955-1974.

(28) Bjerg, P. L.; Rugge, K.; Pedersen, J. K.; Christensen, T. H. Distribution of Redox-Sensitive Groundwater Quality Parameters Downgradient of a Landfill (Grindsted, Denmark). Environ. Sci. Technol. 1995, 29, 1387-1394.

(29) Vandevivere, P.; Baveye, P. Relationship between Transport of Bacteria and Their Clogging Efficiency in Sand Columns. Appl. Environ. Microbiol. 1992, 58, 2523-2530.

(30) Vandevivere, P.; Baveye, P.; Delozada, D. S.; Deleo, P. Microbial Clogging of Saturated Soils and Aquifer Materials - Evaluation of Mathematical-Models. Water Resour.Res. 1995, 31, 2173-2180.

(31) Cunningham, A. B.; Characklis, W. G.; Abedeen, F.; Crawford, D. Influence of Biofilm Accumulation on Porous-Media Hydrodynamics. Environ. Sci. Technol. 1991, 25, 1305-1311. (32) Vrionis, H. A.; Anderson, R. T.; Ortiz-Bernad, I.; O'Neill, K. R.; Resch, C. T.; Peacock, A. D.; Dayvault, R.; White, D. C.; Long, P. E.; Lovley, D. R. Microbiological and geochemical heterogeneity in an in situ uranium bioremediation field site. Appl. Environ. Microbiol. 2005, 71, 6308-6318.

(33) Li, L.; Steefel, C. I.; Kowalsky, M. B.; Englert, A.; Hubbard, S. S. Effects of physical and chemical heterogeneities on solid phase transformation and biomass accumulation associated with uranium bioremediation at Rifle, Colorado. J. Contam. Hydrol. 2009 (in revision). 
(34) Hand, V. L.; Lloyd, J. R.; Vaughan, D. J.; Wilkins, M. J.; Boult, S. Experimental Studies of the Influence of Grain Size, Oxygen Availability and Organic Carbon Availability on Bioclogging in Porous Media. Environ. Sci. Technol. 2008, 42, 1485-1491. 